\title{
A NOTE ON THE RAMSEY NUMBER OF EVEN WHEELS VERSUS STARS
}

\author{
Sh. Haghi And H.R. Maimani \\ Mathematics Section, Department of Basic Sciences \\ Shahid Rajaee Teacher Training University \\ P.O. BOX 16783-163, Tehran, Iran \\ School of Mathematics \\ Institute for Research in Fundamental Sciences (IPM) \\ P.O. BOX 19395-5746, Tehran, Iran \\ e-mail: sh.haghi@yahoo.com
}

\begin{abstract}
For two graphs $G_{1}$ and $G_{2}$, the Ramsey number $R\left(G_{1}, G_{2}\right)$ is the smallest integer $N$, such that for any graph on $N$ vertices, either $G$ contains $G_{1}$ or $\bar{G}$ contains $G_{2}$. Let $S_{n}$ be a star of order $n$ and $W_{m}$ be a wheel of order $m+1$. In this paper, we will show $R\left(W_{n}, S_{n}\right) \leq 5 n / 2-1$, where $n \geq 6$ is even. Also, by using this theorem, we conclude that $R\left(W_{n}, S_{n}\right)=5 n / 2-2$ or $5 n / 2-1$, for $n \geq 6$ and even. Finally, we prove that for sufficiently large even $n$ we have $R\left(W_{n}, S_{n}\right)=5 n / 2-2$.
\end{abstract}

Keywords: Ramsey number, star, wheel, weakly pancyclic.

2010 Mathematics Subject Classification: 05C55, 05D10.

\section{REFERENCES}

[1] S. Brandt, R. Faudree and W. Goddard, Weakly pancyclic graphs, J. Graph Theory 27 (1998) 141-176. doi:10.1002/(SICI)1097-0118(199803)27:3〈141::AID-JGT3〉3.0.CO;2-O

[2] G. Chartrand and O.R. Oellermann, Applied and Algorithmic Graph Theory (Mc Graw-Hill Inc, 1993).

[3] Y. Chen, Y. Zhang and K. Zhang, The Ramsey numbers of stars versus wheels, European J. Combin. 25 (2004) 1067-1075.

doi:10.1016/j.ejc.2003.12.004

[4] V. Chvátal and F. Harary, Generalized Ramsey theory for graphs, III. Small offdiagonal numbers, Pac. J. Math. 41 (1972) 335-345.

doi:10.2140/pjm.1972.41.335 
[5] G.A. Dirac, Some theorems on abstract graphs, Proc. Lond. Math. Soc. 2 (1952) 69-81.

doi:10.1112/plms/s3-2.1.69

[6] R.J. Faudree and R.H. Schelp, All Ramsey numbers for cycles in graphs, Discrete Math. 8 (1974) 313-329.

doi:10.1016/0012-365X(74)90151-4

[7] J.M. Hasmawati, Bilangan Ramsey untuk Graf Bintang Terhadap Graf Roda (Tesis Magister, Departemen Matematika ITB, Indonesia, 2004).

[8] E.T. Hasmawati, E.T. Baskoro and H. Assiyatun, Star-wheel Ramsey numbers, J. Combin. Math. Combin. Comput. 55 (2005) 123-128.

[9] A. Korolova, Ramsey numbers of stars versus wheels of similar sizes, Discrete Math. $292(2005)$ 107-117. doi:10.1016/j.disc.2004.12.003

[10] B. Li and I. Schiermeyer, On star-wheel Ramsey numbers, Graphs Combin. 32 (2016) 733-739.

doi:10.1007/s00373-015-1594-6

[11] V. Rosta, On a Ramsey-type problem of J.A. Bondy and P. Erdös, II, J. Combin. Theory Ser. B 15 (1973) 105-120. doi:10.1016/0095-8956(73)90036-1

[12] Surahmat and E.T. Baskoro, On the Ramsey number of a path or a star versus $W_{4}$ or $W_{5}$, in: Proceedings of the 12th Australasian Workshop on Combinatorial Algorithms (Bandung, Indonesia, July, 2001) 174-179.

[13] Y. Zhang, T.C.E. Cheng and Y. Chen, The Ramsey numbers for stars of odd order versus a wheel of order nine, Discrete Math. Algorithms Appl. 1 (2009) 413-436. doi:10.1142/S1793830909000336

[14] Y. Zhang, Y. Chen and K. Zhang, The Ramsey numbers for stars of even order versus a wheel of order nine, European J. Combin. 29 (2008) 1744-1754.

doi:10.1016/j.ejc.2007.07.005

Received 14 June 2016

Revised 1 December 2016

Accepted 1 December 2016 